\title{
CONSEQUÊNCIAS DO NEODESENVOLVIMENTISMO BRASILEIRO PARA AS POLÍTICAS PÚBLICAS DE CRIANÇAS E ADOLESCENTES: reflexões sobre a implantação da Usina Hidrelétrica
} de Belo Monte

\author{
Assis da Costa Oliveira \\ Universidade Federal do Pará (UFPA)
}

CONSEQUÊNCIAS DO NEODESENVOLVIMENTISMO BRASILEIRO PARA AS POLÍTICAS PÚBLICAS DE CRIANÇAS E ADOLESCENTES: reflexões sobre a implantação da Usina Hidrelétrica de Belo Monte

Resumo: 0 artigo objetiva analisar o processo vivenciado na cidade de Altamira, estado do Pará, antes a construção da Usina Hidrelétrica de Belo Monte, voltando-se para a problematização de como as políticas públicas para crianças e adolescentes são afetadas pelos problemas decorrentes desta grande obra. Através da análise de dados estatísticos comprova a precarização acelerada de índices sociais ligados à violência sexual, ato infracional e uso de drogas. Constata também, a incapacidade operacional de as instituições do Sistema de Garantia de Direitos darem conta da demanda atual, fruto da inexistência de planejamento e investimentos prévios, assim como a demora na execução das políticas compensatórias que, por serem obrigações da empresa privada que administra a obra, instaura situação paradoxal de privatização dos direitos humanos, levando à inversão dos papéis de Estado e empresa.

Palavras-chaves: Neodesenvolvimentismo, políticas públicas, crianças e adolescentes, Usina Hidrelétrica de Belo Monte.

CONSEQUENCES OF BRAZILIAN NEO-DEVELOPMENTALISM FOR PUBLIC POLICIES OF CHILDREN AND TEENAGERS: reflections about the implementation of Belo Monte's Hydroelectric factory

Abstract: The article aims to analyze the process experienced in the city of Altamira, Para state, in relation to the construction of Belo Monte's Hydroelectric Factory, turning to the questioning of how public policies for children and adolescents are affected by the problems arising from this great work. Analyzing statistical data proves the precariousness of accelerated social indicators related to sexual violence offenses, violator act and drug use. It is also noted, the operational inability of institutions of the Warranty of Rights System to support the current demand, due to the lack of previous planning and investments, as well as the delay in the execution of compensatory policies that, being obligations of private company that manages the work, it establishes the paradoxical situation of human rights privatization, leading to reversal of the roles of state and business.

Keywords: public policies, children and adolescents, Belo Monte's Hydroelectric Factory, violence, human rights. 


\section{INTRODUÇÃO}

O novo cenário do desenvolvimentismo brasileiro, iniciado na década de 1990, e com continuidades ideológicas e práticas nos governos federais que se sucederam, tem, no entender de Bermann, a construção e operacionalização da Usina Hidrelétrica de Belo Monte (UHE Belo Monte) como "paradigma para o processo de expansão da fronteira hidrelétrica na bacia amazônica" (BERMANN, 2012, p. 7).

O "paradigma Belo Monte" leva em consideração um conjunto de planejamentos estratégicos do governo federal que prevê a implantação de 30 hidrelétricas até 2020 na área correspondente a Amazônia legal, num total de 48 a serem instaladas em todo o Brasil, como partes do Programa de Aceleração do Crescimento (PAC), em suas versões um e dois, do Plano Decenal de Energia (2011-2020) e o Plano Nacional de Energia². 0 novo desenvolvimentismo brasileiro reforça 0 papel do território amazônico enquanto fronteira de expansão do capitalismo pela exploração dos recursos agrominerais e hídricos, projetando a instalação de hidrelétricas nos principais rios amazônicos (Araguaia, Madeira, Tapajós, Teles Pires, Tocantins e Xingu) como medidas necessárias para 0 desenvolvimento econômico e seguridade energética da nação, sendo a UHE Belo Monte a maior destas grandes obras e a que vai abrir a possibilidade R. Pol. Públ., São Luís, v. 17, n.2, p. 289 - 302, jul./dez. 2013 de exploração mineral da bacia do Xingu, tão ou mais rica em minérios do que a de Carajás; esta, no sudeste paraense.

A UHE Belo Monte, planejada desde os idos da década de 1970 do século $X X I$, só entrou em processo de planejamento efetivo para a construção em 2005, após ser definida como a "menina dos olhos" do PAC do governo Lula ${ }^{3}$. Projetada para ser instalada no rio Xingu, a $40 \mathrm{~km}$ rio abaixo da cidade de Altamira, estado do Pará, na região conhecida por Volta Grande (área em que o rio dá um giro de quase 270 graus e tem desnível de mais de 100 metros), tem potência instalada de 11.233 MW, sendo a maior usina hidrelétrica inteiramente brasileira e a terceira maior hidrelétrica do mundo, porém com capacidade média de apenas 4.428 MW, ou seja, 39\% do potencial máximo, devido a redução da vazante do Xingu nos períodos de junho a outubro, conhecido localmente como época do verão amazônico.

Desde a retomada das negociações e disputas que envolvem a construção da UHE Belo Monte, um dos pontos pouco salientado pelo debate público em relação à grande obra é: quais os impactos gerados por esta grande obra para a situação das crianças e dos adolescentes e as políticas e instituições públicas destinadas a este público? Esta problemática representa um recorte geracional de um contexto mais amplo que envolve a consideração à denominada população atingida pela grande obra e a 
capacidade do Estado brasileiro de responder às demandas geradas pela nova conjuntura socioambiental.

Trata-se de uma análise comparativa dos últimos três anos (2010-2012), período que coincide com o da emissão da Licença Prévia da UHE Belo Monte pelo IBAMA, em fevereiro de 2010, e sinaliza a entrada num novo ciclo histórico de desenvolvimentismo para a bacia do Xingu, em especial a cidade de Altamira, no qual as consequências sociogeracionais precisam ser dimensionadas para garantir subsídios à avaliação crítica do grau de efetividade dos direitos humanos das crianças e dos adolescentes, e de projeção comparativa com outros cenários similares na Amazônia.

\section{GEOPOLÍTICA DO DESENVOLVIMENTO} NO CENÁRIO AMAZÔNICO: compreendendo o cenário de produção das "vítimas do neodesenvolvimentismo"

\section{As transformações da} economia mundial ocorridas no último quarto do século XX vêm, crescentemente, inserindo a América Latina, e a região Amazônica de forma mais específica, numa "nova" geopolítica mundial de exploração dos recursos naturais assentada no investimento econômico em grandes obras - de implantação de redes de infraestrutura, reconversão de atividades e alteração das formas de ocupação do espaço em função dos fluxos transnacionais de acumulação de riqueza (ACSELRAD, 2010) - a fim de aumentar a vinculação aos mercados globais e promover a abertura de novas fronteiras de recursos em proveito da iniciativa privada (CASTRO, 2010).

A diferença do momento atual para outras situações históricas é de que há crescente subida de preços não de uma commodity isolada - a exemplo do que ocorreu com a soja, o café, o látex e o açúcar, em períodos específicos - mas sim a elevação geral das commodities agrícolas e minerais ${ }^{4}$, provocados pelo aumento da procura internacional, sobretudo dos Estados Unidos, Europa e Ásia (China e Japão), o que gera, entre outros efeitos, processo de devastação sobre o mercado de terras e recursos naturais na Amazônia por meio da subida vertiginosa do preço da terra, revisão/flexibilização da legislação protetiva do meio ambiente e dos povos tradicionais ${ }^{5}$, e acirramento dos conflitos sociais nos espaços de expansão das fronteiras capitalistas (ALMEIDA, 2005; MALERBA E MILANEZ, 2012; MESQUITA 2011).

No contexto regional não se pode deixar de analisar a emergência da Integração das Infraestruturas Regionais Sul-Americanas (IIRSA) e do PAC enquanto iniciativas voltadas à realização de obras de infraestrutura dos setores de transporte, energia e comunicação, sendo a IIRSA uma articulação dos governos de 12 países latino-americanos, elaborada no ano de 2000, com objetivo de fortalecê-los 
economicamente no mercado global por meio da realização de 31 projetos de grande escala (ditos projetos-âncora), a partir do qual 0 governo brasileiro centrou esforços para internalizar a "nova" integração latinoamericana, seja com a edição de Planos Plurianuais (Avança Brasil 2000/2003 e Brasil de Todos 2004/2007) ou do PAC, e no mais recente PAC 2, lançado em 2010.

Tais políticas reproduzem concepções hegemônicas de desenvolvimento capitalista que são causas históricas do processo de exclusão e desigualdade social das populações locais da Amazônia. 0 cenário das grandes obras é indissociável de perspectiva de desenvolvimento centrada nas demandas econômicas de caráter nacional e internacional que justificam a elaboração de obras de intenso impacto socioambiental que fazem da exploração/exportação de recursos naturais - transformados em commodities - 0 sustentáculo da pretendida integração de povos e culturas dentro de sistema capitalista de abrangência mundial (VERDUM, 2007).

As populações locais pouco são escutadas e, quando muito, arcam apenas com os danos socioambientais gerados pelas grandes obras, constituindo-se em populações atingidas por empreendimentos que, só no âmbito hidrelétrico, para o decênio 2007/2016, representa o contingente de aproximadamente 101 mil pessoas ou 25 mil famílias, segundo dados de Nuti (2007); isto, evidentemente, levando-se em conta apenas aqueles que terão R. Pol. Públ., São Luís, v. 17, n.2, p. 289 - 302, jul./dez. 2013 que ser removidos de seu local de origem para dar lugar à obra (chamados de população diretamente atingida que necessita ser reassentada) - a quantidade de pessoas afetadas indiretamente pelas grandes obras é ainda mais nebulosa na computação prévia e planejada, pois os referenciais não podem ser traçados apenas numa perspectiva objetiva de definição geográfica dos impactos socioambientais, trata-se de elementos afetivos, simbólicos, subjetivos e culturais que permeiam, de maneira coletiva ou individual, a compreensão das formas de danos a serem sofridas pelas "vítimas do neodesenvolvimentismo", em especial crianças, adolescentes, mulheres e comunidades tradicionais.

No âmbito da UHE Belo Monte as informações presentes do Estudo de Impacto Ambiental (EIA) definem uma quantidade de 19.242 pessoas - 2.822 pessoas de comunidades rurais e 16.420 da área urbana (LEME, 2009a, p. 37) - numa área delimitada de $1.522 \mathrm{Km}^{2}$ que representa apenas o quantitativo populacional que terá de se deslocar dos municípios de Altamira, Brasil Novo, Senador José Porfírio e Vitória do Xingu, afetada diretamente pelo alagamento de áreas devido ao represamento do rio Xingu, e da implantação da estrutura física e canteiro de obras da hidrelétrica. Esta divisão entre população diretamente atingida e indiretamente atingida, ou área de influência direta e indireta, são classificações técnico-burocráticas 
definidas pelo IBAMA que desconsideram dinâmica muito mais complexa dos impactos socioambientais ocasionada pelo intenso processo de intervenção ambiental e ocupação humana deflagrada pela grande obra, marcado pelo caráter da imprevisibilidade e da imprecisão de planejamento prévio.

0 recorte da população infantojuvenil definida como afetada diretamente pelos impactos socioambientais do empreendimento é mensurado no EIA por 5.864 crianças e adolescentes de até 14 anos no espaço urbano e 905 para o espaço rural, totalizando 6.769; além de 1.142 adolescentes de 15 a 17 anos residentes da área urbana e 176 residentes da área rural diretamente afetada (LEME, 2009a, p. 38).

Segundo Magalhães, Marin e Castro (2009), as especificidades populacionais por faixa etária foram subdimensionadas e, em alguns casos, erroneamente computadas, como na definição da população rural existente na denominada Área Diretamente Afetada (ADA) que utiliza uma média de 3,14 pessoas por "grupo doméstico" (LEME, 2009b, p. 78) e, logo em seguida, apresenta em porcentagem a faixa etária da população infanto-juvenil residente como sendo de $27,10 \%$ para crianças e adolescentes até 14 anos e de apenas 5,3\% para adolescentes de 15 a 17 anos, quantidade justificada "pela rede deficitária do ensino zona rural, favorecendo a saída dessa população [adolescente] - para concluir a etapa do ensino fundamental ou se ingressar no ensino médio nos centros de influência." (LEME, 2009b, p. 83)

\section{Conforme}

destacam

Magalhães, Marin e Castro (2009), a análise subsequente do RIMA deslegitima a demografia etária apresentada anteriormente porque desconsidera ampla bibliografia existente sobre as comunidades rurais da região que define uma média entre 5,5 e 7 pessoas por grupo doméstico, além de não atentar para o fato de que esta "saída" da população adolescente é sazonal ou passageira, não representando a realidade sociocultural dos arranjos familiares existentes e, com isso, cometendo um grave erro de análise cuja consequência é a própria impossibilidade de dimensionamento real da população infanto-juvenil existente nas comunidades rurais da região da Volta Grande do Xingu.

Além disso, os dados demográficos gerais e por faixa etária foram obtidos até fevereiro de 2008 - período de término da pesquisa de campo do EIA - o que representa etapa distante daquela iniciada com 0 aumento do fluxo migratório deflagrado com a emissão da Licença Prévia do empreendimento, no ano de 2010, e cujo adensamento populacional das ADA não foi objeto de verificação pelos estudos especializados para licenciamento do empreendimento.

Assim, a quantidade de crianças e adolescentes afetadas pela grande obra não 
está caracterizada nos estudos prévios elaborados, apenas aparecem componentes estatísticos gerais - como mortalidade infantil e taxa de fecundidade, elaborados a partir do enfoque municipal e obtidos de órgãos oficiais - e referenciais aos aparelhos institucionais, como escolas e postos de saúde, que precisariam atender a demanda deste público, mas sua quantidade e qualificação precisas ou minimamente próximas da real situação são deficitárias.

Com isso, volta-se a situação de imprevisibilidade e de imprecisão dos impactos sociogeracionais ante a impossibilidade de dimensionar a quantidade de crianças $e$ adolescentes que serão atingidas por este empreendimento e, mesmo que esta fosse feita pelos estudos prévios, muito provavelmente só levaria em consideração a população infantojuvenil classificada como diretamente atingida, desconsiderando ou tornando invisível uma realidade mais ampla de afetação, além de não analisar aspectos identitários, socioculturais, afetivos, políticos e ambientais que influenciam diretamente na dinâmica de territorialização e socialização da população local em interação com a população atraída pela grande obra 6 .

Desse modo, ficou prejudicada "de partida" ou de forma prévia a definição dos problemas públicos específicos da população infanto-juvenil, pré-requisito fundamental para o planejamento estratégico das políticas públicas que necessitam atender a demanda anterior $e$ decorrente do processo de adensamento populacional ocasionado pela UHE Belo Monte.

Esta constatação é fundamental para a compreensão dos limites da intervenção estatal nos territórios impactados por grandes obras, como a UHE Belo Monte: trata-se da impossibilidade de planejamento e investimento prévios que tenham eficácia de atuação sobre a demanda real devido a demanda diagnosticada não apresentar caracterização coerente com a realidade presente no período de pesquisa de campo do EIA-RIMA da UHE Belo Monte e muito menos dos estágios posteriores à pesquisa, indicando, assim, no recorte geracional, 0 déficit prévio da estruturação das políticas públicas e da análise das condições de vida de crianças e de adolescentes residentes na região impactada pelo empreendimento.

Todavia, é possível definir alguns aspectos deste impacto levando-se em conta 0 caráter processual da grande obra, ou seja, como os danos vão se configurando a cada nova etapa da grande obra, que coincide com uma nova etapa de intervenção sobre o meio ambiente e reordenamento da presença humana na região, dentre as quais a de crianças e de adolescentes.

\section{MIGRAÇÃO, MARGINALIZAÇÃO E VIOLÊNCIA}

Os impactos socioambientais gerados pelas grandes obras na Amazônia 
devem ser compreendidos enquanto parte do encontro conflitivo e antagônico de formas de organização da vida social, ou, como aborda Hébette (2004), no confronto de modos de vida e de produção com consequências globais e permanentes, sinalizando que 0 desenvolvimento da fronteira capitalista se dá necessariamente com a geração de vários danos aos grupos sociais locais e, ao mesmo tempo, de formulação de "oportunidades capitalistas" travestidas em investimentos compensatórios, incentivo à instalação de empreendimentos do agronegócio e adoçamento das elites governamentais.

Os grupos infanto-adolescentes se inserem neste processo conflitivo e danoso enquanto parte do conjunto populacional afetado, mas certamente, sobre eles, incidem questões específicas que precisam ser mais bem trabalhadas na análise crítica.

Uma primeira situação é o modo como o rápido e intenso deslocamento de contingentes humanos para os locais de implantação de grandes obras repercute diretamente nas condições de vida da população migrante e dos habitantes nativos, produzindo uma acelerada agudização dos índices sociais de forma a visibilizar a presença de situação generalizada de vulnerabilização socioeconômica de vários segmentos da população e a correlata incapacidade de planejamento institucional para prever e atender esta "nova demanda".
Apesar de os estudos prévios trazerem sempre estimativa da quantidade populacional que imaginasse que se transferirá, de maneira permanente ou temporária, a situação é complexa e acaba por transcender as possibilidades de planejamento. Segundo 0 relatório DhESCA (2011) sobre o Complexo Hidrelétrico do rio Madeira, a migração para o município de Porto Velho/RO foi $22 \%$ superior ao estipulado pelo EIA do projeto.

$\mathrm{Na}$ atualidade, conhecer a população de Altamira é situação objeto de disputa pela precisão dos números. 0 Censo/2010 do Instituto Brasileiro de Geografia e Estatística (IBGE) estabelece a marca de 99.070 pessoas, sendo que o Censo anterior, de 2000 , evidenciou a presença de 77.439 pessoas. Todavia, técnicos da Secretaria Municipal de Planejamento da Prefeitura Municipal de Altamira trabalhavam, em 2012, com estimativa populacional de 126.000 pessoas, cuja base de cálculo é a produção de lixo e a demanda por atendimento no Hospital Municipal São Rafael.

A demografia estimada do município representa crescimento de $60 \%$ da população existente há 10 anos e aumento de quase $30 \%$ entre a população identificada no Censo/2010 e aquela calculada pelos técnicos da burocracia local7.

Com isso, é preciso analisar os impactos sociogeracionais. A rapidez de formação do excesso populacional "congestiona" (ou abarrota) a capacidade do 
Estado, da sociedade e das empresas de ajustar/ampliar os serviços e bens públicos para acesso e utilização de crianças e adolescentes, ocasionando, por exemplo, a impossibilidade de matrícula em escolas públicas - já cheias de estudantes - ou de atendimento nos hospitais, assim como de utilização de praças públicas devido estarem totalmente sucateadas; isto tudo, pensando 0 contexto na cidade de Altamira na atualidade.

\begin{tabular}{|c|l|c|c|c|c|c|}
\hline 4 & $\begin{array}{l}\text { Dependente } \\
\text { químico }\end{array}$ & 11 & - & 04 & 69 & 129 \\
\hline 5 & $\begin{array}{l}\text { Adolescente } \\
\text { em conflito } \\
\text { com a lei }\end{array}$ & - & 19 & 77 & 93 & 118 \\
\hline 6 & $\begin{array}{l}\text { Conflitos } \\
\text { familiares }\end{array}$ & 94 & 85 & 83 & 149 & 374 \\
\hline
\end{tabular}

FONTE: Conselho Tutelar de Altamira (2008, 2009, 2010, 2011 e 2012).

Para a facilitação da percepção divulgados pelo Conselho Tutelar de Altamira (2008, 2009, 2010, 2011 e 2012) nos últimos anos permite a compreensão comparativa da trajetória desenvolvida por algumas questões atendidas pela instituição. 0 quadro abaixo apresenta de maneira sistematizada os dados conforme a classificação conceitual definida nos relatórios anuais da instituição.

QUADRO 1: Tabela comparativa do atendimento do Conselho Tutelar de Altamira

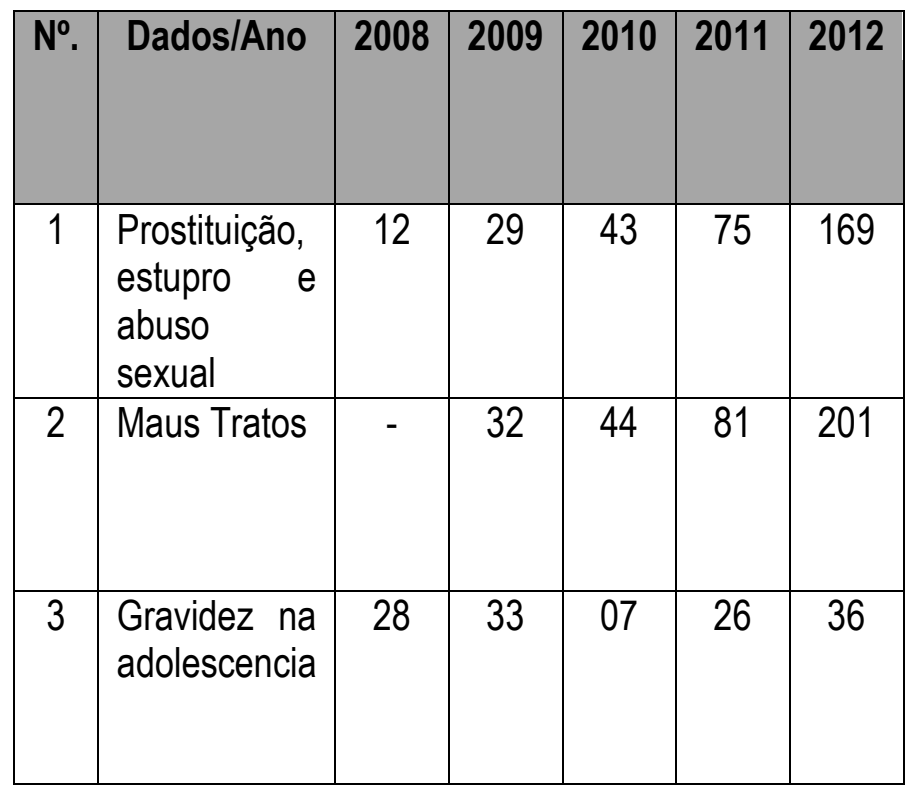

R. Pol. Públ., São Luís, v. 17, n.2, p. 289 - 302, jul./dez. 2013

\section{Conselho Tutelar de Altamira}

口 2008 a $2009 \quad 2010 \square 2011 \square 2012$

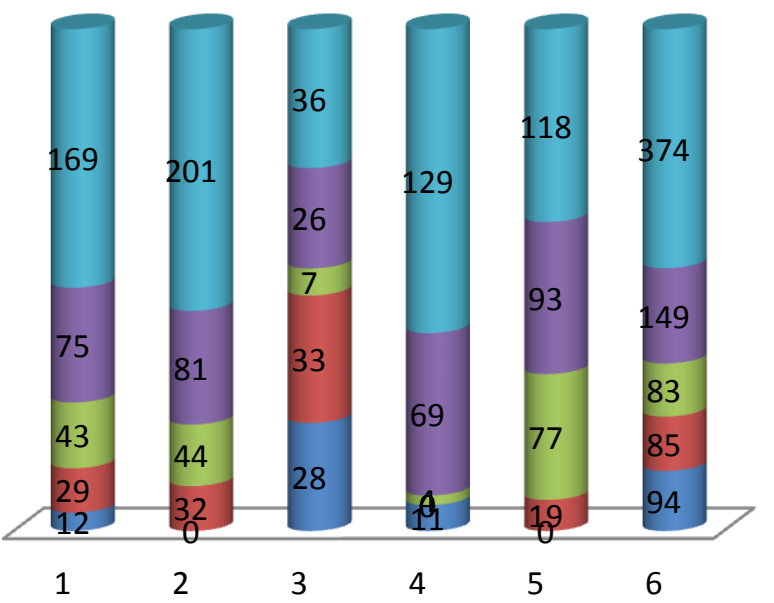

FONTE: Pinho e Oliveira (2012). 
Além dos dados do Conselho Tutelar, recentemente Pinho e Oliveira (2012) divulgaram pesquisa em que sistematizaram os dados obtidos dos processos judiciais que versam sobre crimes sexuais contra crianças e adolesentes na $3^{a}$ e $5^{a}$ Varas do Forum de Justiça da Comarca de Altamira, no período compreendido entre 1957 e 2012. Os dois gráficos abaixo foram retirados do relatório de Pinho e Oliveira (2012) para apresentação da sistematização gráfica realizada.

GRÁFICO 2: Desenvolvimento histórico dos casos judicializados em Altamira em intervalo de ano a ano

\section{Quantidade de processos}

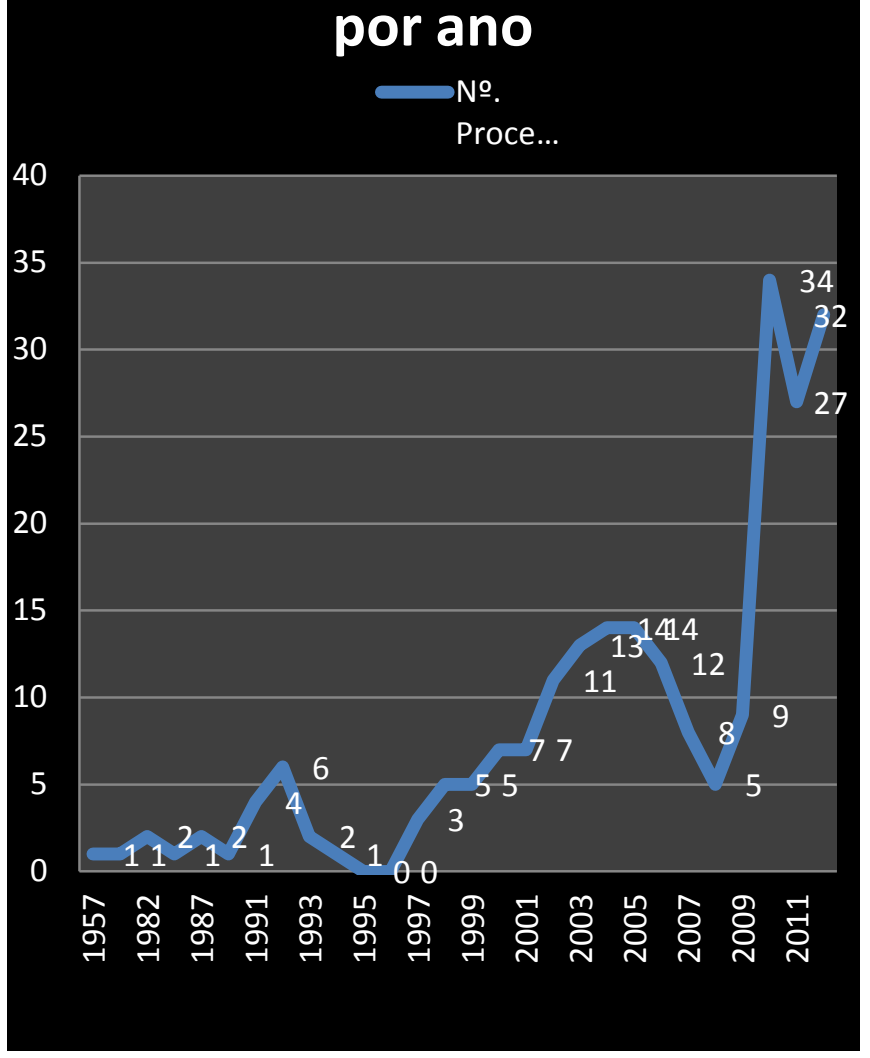

GRÁFICO 3: Desenvolvimento histórico dos casos judicializados em Altamira em intervalo de três anos

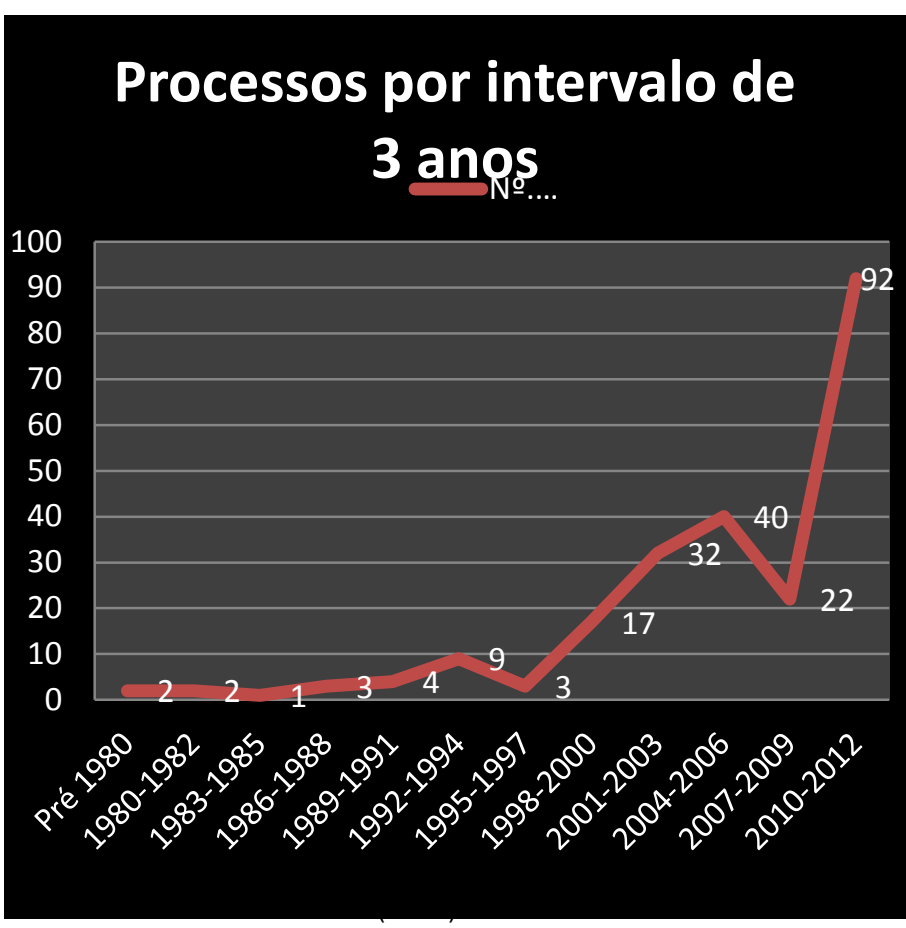

De modo geral, os dados obtidos com o Conselho Tutelar de Altamira e na pesquisa de Pinho e Oliveira (2012) indicam um crescimento da violação de direitos de crianças e adolescentes no município de Altamira nos últimos três anos (2010-2012) visibilizando a presença de situação singular nunca antes vista neste município - de generalização da vulnerabilização social de crianças e adolescentes e, ao mesmo tempo, do acionamento das instituições da rede de proteção para intervirem sobre esta demanda.

Os dados do Conselho Tutelar de Altamira apontam uma agudização mais intensa nas situações de "prostituição, estupro e abuso sexual" e "adolescente em conflito com a lei", pois a análise comparativa identifica uma 
quantidade de duas a quatro vezes maior entre os dados de 2009 e aqueles que aparecem a partir de 2010. Porém, a maior variação ano/ano, a partir de 2010, é encontrada nos dados de "dependente químico", "conflitos familiares" e "maus tratos".

Em relação às informações apresentadas no relatório de Pinho e Oliveira (2012), percebe-se, como os próprios autores indicam, um crescimento da média de casos na $1^{\text {a }}$ década do século XXI de 10 casos/ano para a média atual de 30 casos/ano, cujo recorte de aceleração brusca a partir de 2010 é analisado pelos autores a partir de três hipóteses explicativas: (1) a criação de instituições importantes para o enfrentamento estratégico da violência sexual contra crianças e adolescentes no município de Altamira nos últimos anos, com destaque para a Vara da Infância e da Juventude, a $5^{\mathrm{a}}$ Vara especializada nos crimes de violência contra a criança e o adolescente, e o Núcleo de Atendimento Especializado da Criança e do Adolescente da Defensoria Pública do Estado do Pará (DPE), além da presença de um Centro de Referência Especializado de Assistência Social (CREAS), os quais fortaleceram a atuação qualificada neste enfrentamento; (2) sensibilização da sociedade para a identificação e denúncia dos casos de violência sexual, fruto da mobilização social por meio da organização de companhas, passeatas, cursos de formação e divulgação da mídia, e da atuação da Comissão Municipal de R. Pol. Públ., São Luís, v. 17, n.2, p. 289 - 302, jul./dez. 2013
Enfrentamento da Violência Sexual Contra Crianças e Adolescentes de Altamira/PA, que conseguiram, ao longo destes anos - apesar desta mobilização social ser histórica, originada com o caso dos meninos emasculados de Altamira, no início da década de 1990 - manter no debate público a problematização da violência sexual e de suas formas de enfrentamento; (3) a influência do processo de construção da UHE Belo Monte, sobretudo em decorrência do fluxo migratório e vulnerabilização de famílias, crianças, adolescentes e mulheres.

Constata-se, pelos dados estatísticos apresentados, a precarização da situação de vida das crianças e dos adolescentes ocasionado pela violação de seus direitos. Estas informações constituem-se naquelas que chegam aos órgãos públicos, portanto, as que obtêm acesso à rede de proteção e tornam-se públicas, sendo, provavelmente, ainda uma parcela da quantidade de casos reais de violação de direitos das crianças e dos adolescentes existentes no município, e isto, enfatiza-se, porque a maioria dos casos denunciados é relativa ao espaço urbano, os povos e comunidades tradicionais e demais populações rurais têm realidades pouco conhecidas e quase não são atendidas pelas instituições da rede de proteção.

É necessário compreender os impactos sociais acima definidos como situados numa perspectiva de rede ou 
relacional em dois sentidos: (1) a vulnerabilização social das famílias e comunidades implica necessariamente na vulnerabilização social das crianças e dos adolescentes, com atenção especial para as famílias migrantes $e$ as comunidades tradicionais no entorno do canteiro de obras da hidrelétrica, pois as primeiras situam-se em condição de pobreza, consequência do desemprego e da ausência de políticas sociais que as fortaleça, sendo parte do processo de sobrevivência a colocação das crianças em situações de risco, enquanto as comunidades tradicionais localizadas próximas dos canteiros de obras sofrem, quase sempre, com o impacto de grande leva de trabalhadores, na maioria homens, que inflaciona o mercado de bebidas alcoólicas, drogas e serviços sexuais, o que pode levar a inserção de crianças e adolescentes que convivem, direta ou indiretamente, com tal situação, num ciclo de violação de direitos e mudança de hábitos; (2) a presença, em muitas situações, da emergência de mais de uma violência social num caso, a exemplo da relação entre uso de drogas com a violência sexual, situados, por vezes, num contexto de conflitos familiares ou na situação de risco dos espaços em que as atividades são desenvolvidas (nos bares, ruas, casas de espetáculo, entre outros).

No contexto da UHE Belo Monte, a situação das crianças e dos adolescentes indígenas exige preocupação especial. A elaboração do Plano Emergencial, em setembro de 2010, entre povos indígenas, Norte Energia S.A. (NESA) e Fundação Nacional do Índio (FUNAI), garantiu a cada aldeia indígena da região do Xingu o montante de 30 mil reais por mês, para serem gastos com o que quisessem. Com isso, as "listas de compras" demandavam produtos industrializados, marmitas e bebidas alcoólicas, desencadeando uma "explosão de consumismo" nas aldeias e na cidade cujos reflexos mais visíveis estão na saúde das crianças e nos conflitos geracionais.

Há relatos de aldeias indígenas em que há ingestão diária de dois litros de refrigerante por mulheres e crianças, sem contar as dezenas de caixas de açúcar, óleo vegetal e biscoitos que se aglomeram na Casa do Índio de Altamira e nas próprias aldeias, cujo fluxo de consumo intenso exaure em poucas semanas os estoques e fazem girar a engrenagem das listas, novamente.

Não apenas as crianças e adolescentes indígenas estão ingerindo mais alimentos industrializados ricos em sal, gordura e açúcares, mas a agudização deste processo de inserção de produtos não indígenas tem gerado conflitos entre crianças/adolescentes/adultos e os velhos indígenas, especialmente em relação à bebida alcoólica. Algumas aldeias novas, como a Paranapiona, do povo Parakanã, foram construídas devido a dissidência entre velhos e novos, com aqueles decidindo sair dos locais de convivência para terem mais paz e 
tranquilidade, e manterem suas práticas tradicionais.

\section{CONDIÇÕES DO SISTEMA DE GARANTIA DE DIREITOS DE ATENDER AS “GRANDES” DEMANDAS}

Os impactos do aumento populacional e da precarização das condições de vida, levando em conta o contexto gerado pela UHE Belo Monte, ocasionam a situação de aumento da demanda social pelo acesso às instituições e políticas públicas que não é seguido do aumento estrutural e de recursos humanos nas instituições legalmente responsáveis pelo atendimento de crianças e adolescentes.

Em Altamira, a relação entre demanda social e capacidade socioinstitucional é transversalizada pela imprevisibilidade (explícita ou implícita) de efetivação dos resultados obtidos nos estudos que procuram antecipar a dimensão objetiva dos danos socioambientais para estabelecer medidas compensatórias e recursos financeiros.

A imprevisibilidade remete, necessariamente, ao descompasso entre a dinâmica socioambiental desencadeada pela implantação da grande obra e a capacidade institucional de prever e compensar, no menor tempo possível, as demandas geradas. Um exemplo típico de tal situação na cidade de Altamira é o aumento generalizado do preço dos aluguéis e dos produtos alimentícios, em R. Pol. Públ., São Luís, v. 17, n.2, p. 289 - 302, jul./dez. 2013 decorrência do crescimento populacional ocasionado pela UHE Belo Monte que gerou a impossibilidade das classes populares de arcarem com os reajustes, fazendo-as, de forma espontânea ou organizada, ocupar terrenos desabitados do município para construírem as casas próprias e, concomitantemente, exigirem do poder público medidas efetivas para garantia de políticas de habitação popular.

Esta situação de aumento do custo de vida tem provocado duas consequências diferentes, mas com impacto comum sobre os profissionais que atuam nas instituições públicas no município.

A primeira é a "onda de transferência" acelerada dos profissionais de instituições de âmbito federal e estadual para outras cidades. Pesquisa realizada por Roscoche (2012), entrevistando 40 servidores públicos federais que trabalham em Altamira entre eles professores da Universidade Federal do Pará e do Instituto Federal do Pará, funcionários do Ministério Público Federal e da Política Federal - constatou 0 interesse generalizado de transferência do município, cujos principais motivos foram: preço dos alimentos (para 93\% dos entrevistados); preço dos produtos e serviços $(89 \%$ dos entrevistados); e, precariedade do sistema de saúde do município ( $83 \%$ dos entrevistados).

Para se ter ideia da "onda de transferência" dos funcionários públicos, a Polícia Rodoviária Federal tinha 35 policiais 
atuando em turnos de 6 profissionais até meados de 2012; hoje, em 2013, o efetivo é de 11 profissionais que realizam turnos de apenas 2 pessoas, sendo que a previsão de concurso público a ser realizado em 2013 só possibilitará a destinação de novos policiais em 2014 e houve a paralisação das atividades de monitoramento dos locais de potencial vulnerabilização sexual de crianças e adolescentes ao longo da BR-230 (Rodovia Transamazônica), só atendendo, agora, as situações de emergência. De forma similar, na audiência pública ${ }^{8}$ organizada pela Comissão Parlamentar de Inquérito sobre Tráfico de Pessoas, da Câmara dos Deputados do Congresso Nacional, representantes da Polícia Civil e da Polícia Federal foram taxativos em definir que, na atualidade, existem mais profissionais solicitando remoção do que querendo vir trabalhar no município, e os efetivos atuais de ambas as Polícias não conseguem dar conta do aumento da demanda social.

Em relação aos profissionais que atuam na rede de proteção municipal - como 0 CREAS, Centro de Referência de Assistência Social (CRAS) e Espaço de Convivência de Meninos e Meninas $(\mathrm{ECOM})^{9}$ - a situação não envolve necessariamente a saída do município, mas sim a saída da instituição pública, devido disparidade entre os salários pagos pelo setor público e aqueles encontrados nas diversas empresas terceirizadas da NESA e do Consórcio Construtor Belo Monte (CCBM). Isto acontece de maneira mais nítida com os profissionais que são apenas contratados, dentre eles Psicólogos, Pedagogos, Assistentes Sociais, Auxiliares Administrativos, entre outros, a exemplo do que ocorreu com a equipe do CREAS que, em 2012, foi sucessivamente saindo da instituição para serem contratadas por empresas privadas e a Casa do Migrante; esta última, instituição gerenciada pela NESA, porém integrante da rede socioassistencial da gestão municipal.

A evasão de profissionais das instituições públicas locais impacta diretamente na capacidade do Estado (em seus múltiplos níveis de organização) de gerenciar os conflitos e problemas presentes no território do município e das regiões de abrangência por competência institucional. Essa "incapacidade operacional" se revelou de maneira explícita quando da operação para resgate de 34 mulheres que eram mantidas em prostituição forçada numa boate nas proximidades do sítio Canais e Diques da UHE Belo Monte, em fevereiro de 2013. Esta boate, assim como nove fechadas dias depois na cidade de Altamira, estava com alvará de liberação de funcionamento emitido pela Polícia Civil, a qual só possui uma pessoa para realizar este serviço em toda área de competência, logo, este servidor fazia somente uma vistoria simples nos estabelecimentos e não mais retornava para fiscalizações permanentes.

A outra face da imprevisibilidade dos estudos é o não acompanhamento 
sistemático das mudanças socioambientais ocasionadas ao longo do processo de implantação da UHE Belo Monte. No âmbito da rede de atendimento da criança e do adolescente, poucas instituições realizam 0 levantamento continuado da quantidade e das características da demanda social que é institucionalizada; algumas instituições, como 0 Ministério Público Estadual e a Defensoria Pública Estadual, sequer realizam a sistematização anual dos casos e, com isso, não possuem dados estatísticos que permitam definir o perfil da demanda, nem a análise comparativa ao longo dos anos.

Além disso, as instituições que realizam o levantamento estatístico, como o Conselho Tutelar e o CREAS, não reúnem e relacionam os mesmos num banco de dados unificado que permita a identificação interinstitucional da situação da infância e da adolescência no município.

Por fim, existe também no município de Altamira a necessidade de implantação de algumas instituições consideradas estratégicas para a melhoria da garantia de direitos da criança e do adolescente. No Plano de Ação do Conselho dos Direitos da Criança e do Adolescente de Altamira/PA (CMDCA, 2012) e na Carta formulada na $211^{\mathrm{a}}$ Assembleia Ordinária Descentralizada do Conselho Nacional dos Direitos da Criança e do Adolescente (CONANDA, 2012), realizada em outubro de 2012, na cidade de Altamira, evidencia-se a R. Pol. Públ., São Luís, v. 17, n.2, p. 289 - 302, jul./dez. 2013 reivindicação pela criação de mais dois Conselhos Tutelares em Altamira, um na cidade de Altamira e de outro no distrito de Castelo dos Sonhos, localizado a mais de 900 $\mathrm{Km}$ da sede municipal e que para se deslocar da cidade de Altamira até o distrito demora, em média, dois dias de viagem de carro.

Os documentos públicos apresentam também a reivindicação urgente de criação de instituições públicas para oferta de serviços especializados voltados à criança e ao adolescente, contemplando não apenas 0 município de Altamira, mas também todos os localizados na região do rio Xingu e Transamazônica, sendo eles: Delegacia Especializada de Atendimento ao Adolescente (DATA); Centro de Atendimento Psicossocial Drogas Álcool (CAPS AD); Centro de Internação de Adolescente Infrator; e, unidade do PROPAZ, esta se constituindo numa política do governo estadual de atendimento integral às crianças e aos adolescentes vítimas de violência sexual.

Para se ter uma ideia da realidade local, sem a DATA e o Centro de Internação na região, os adolescentes em situação de ato infracional precisam ser transferidos para a cidade de Santarém, que fica a mais de 800 $\mathrm{Km}$ da cidade de Altamira, para ficarem internados, longe dos familiares $e$ da possibilidade de ressocialização mais eficaz, pois, além de tudo isso, há ainda rixas entre os grupos de adolescentes vindos dos diferentes municípios que, ao se encontrarem no Centro 
de Internação de Santarém, realizam verdadeiras guerras entre facções, com rebeliões e lesões corporais.

Por outro lado, o Fundo Municipal dos Direitos da Criança e do Adolescente há 10 anos não obtém nenhum repasse do governo municipal para garantir a operacionalização das ações do CMDCA de Altamira, mesmo sendo requisito instituído pelo ECA e regulamentado pela Lei Municipal $n^{0}$. 489/93, especialmente no artigo 18, inciso I, que define como receita do Fundo Municipal "[d]otação consignada anualmente no orçamento municipal e as verbas adicionais que a lei estabelecer no decurso de cada exercício [...]" (CAMARA MUNICIPAL DE ALTAMIRA, 1993, p. 9).

\section{CIDADANIA INFANTO-ADOLESCENTE EM TEMPOS DE PRIVATIZAÇÃO DOS DIREITOS HUMANOS VIA POLÍTICAS COMPENSATÓRIAS}

\section{O licenciamento ambiental da} UHE Belo Monte ocorreu, até o momento, por meio da emissão da Licença Prévia $n^{0}$. 342/2010, em fevereiro de 2010, e da Licença de Instalação n. 795/2011, de janeiro de 2011; a primeira delas definindo 40 condicionantes socioambientais e 26 ligadas aos povos indígenas, num total de 66 condicionantes, e a segunda licença acrescentando mais 23 novas condicionantes, num total de 99 condicionantes, aqui incluído também o Projeto
Básico Ambiental $(\mathrm{PBA})^{10}$, que devem ser realizadas pelo empreendedor antes e durante a instalação da hidrelétrica para garantir a preparação do território impactado no intuito de minimizar os impactos socioambientais e oportunizar o desenvolvimento local.

As condicionantes representam um conjunto de medidas de responsabilidade primordial do empreendedor da obra que devem ser garantidas em determinado período de tempo e realizadas enquanto políticas compensatórias. No caso da UHE Belo Monte, estas políticas compensatórias envolvem, a título de exemplificação:

-Construção, reforma e ampliação, pelo empreendedor, da rede de serviços de saúde dos municípios da Área de Influência Direta (AID) para o Programa Saúde da Família (PSF) atuar em unidades adequadas, o que significa construir um hospital de nível médio, 25 Unidades Básicas de Saúde; reforma de dois Centro de Atendimento Psicossocial, quatro hospitais e quatro Unidades Básicas de Saúde (LEME, 2009d, p. 160).

-No Município de Altamira, na área urbana, reforma de duas Escolas Municipais de Ensino Infantil (EMEI), nove Escolas Municipais de Ensino Fundamental (EMEF) e uma Escola Estadual de Ensino Médio (EEEM), além da construção de uma EMEI, quatro EMEF e duas EEEM (NESA, 2012, p. 3).

-Implantação dos sistemas de abastecimento de água, esgotamento sanitário e destinação dos resíduos sólidos urbanos para 
a totalidade da área urbana do município de Altamira, incluindo a vila residencial de apoio às obras (LEME, 2009c, p. 132).

Segundo o Parecer Técnico do IBAMA (2013), de monitoramento do cumprimento das condicionantes, até janeiro de 2013 apenas 19\% delas foram cumpridas integralmente pela NESA. A avaliação do IBAMA (2013) também destaca uma série de medidas em atraso, dentre elas: atraso no cronograma das obras de saneamento básico e de infraestrutura urbana das cidades de Altamira, Vitória do Xingu e dos sítios Belo Monte e Belo Monte do Pontal; não cumprimento no prazo estipulado para término do cadastramento socioeconômico da população atingida; atraso na entrega das obras de saúde planejadas; e, o atraso na definição das áreas na implementação das residências dos trabalhadores em Altamira.

Por outro lado, estas políticas compensatórias, ao transferirem para a iniciativa privada a responsabilidade pelo financiamento e/ou gerenciamento de ações que visam a garantia de direitos humanos básicos da população, colocam em questão 0 cenário de privatização dos direitos e da reconfiguração do papel estatal.

A elaboração de condicionantes para emissão do licenciamento ambiental colocou uma série de questões socioambientais com responsabilidade de concretização do empreendedor privado, é dizer, a NESA, consórcio que ganhou a R. Pol. Públ., São Luís, v. 17, n.2, p. 289 - 302, jul./dez. 2013 licitação de construção da hidrelétrica e que, agora, assume o papel do Estado, cabendo-Ihe a formulação e administração de diversas políticas públicas que colocam em xeque a própria percepção sobre 0 Estado e a cidadania, resultando na aprendizagem nefasta de que o empreendedor privado é Estado, ou assume deveres/papéis que a este último caberia legalmente, apesar de historicamente ausente por estas paragens mais ao norte do país.

Tal competência empresarial gera, em consequência, uma concentração de poder sobre o tempo de execução e as formas de implementação das políticas compensatórias que evidenciam um potencial de controle político-territorial somente vistos em cenários de ausência histórica da atuação estatal e de investimento econômico e simbólico num determinado agente não estatal que passa a controlar diversos mecanismos de intervenção sobre o território e as populações locais, como a implantação de todo o saneamento básico e de vários equipamentos de saúde na cidade de Altamira, que não trazem apenas uma inversão do papel empresa/Estado, mas institui um "novo contrato social" baseado na introdução de um terceiro elemento na relação entre 0 cidadão e Estado que passa a ter o poder de determinar as condições de produção desta relação e as formas de ressignificação de ambos pela linguagem e pelos recursos das políticas compensatórias, que são muito mais do que investimentos de mitigação dos 
impactos negativos da UHE Belo Monte; são os elementos para a produção de um discurso de autoridade e para a legitimação de um sujeito nas relações de poder.

Trata-se de políticas públicas deslocadas para atendimento pelo empreendedor privado, que deveriam ser menos pensadas enquanto medidas compensatórias pelos impactos negativos e mais no sentido de promoverem 0 estabelecimento de condições para a melhoria do desenvolvimento e da qualidade de vida local, com efeitos que se estendam para 0 período pós-Belo Monte, é dizer, para depois do término de construção da hidrelétrica.

A responsabilização do empreendedor é necessária, mas ela não pode ser feita à custa da desresponsabilização do Estado para com seus deveres constitucionais de garantia de direitos à população local.

Nesse sentido, o CMDCA/Altamira tem promovido duas linhas de ações estratégicas que visam responsabilizar 0 empreendedor privado sem desconsiderar os deveres do Estado brasileiro: (1) alinhamento do PBA da UHE Belo Monte com o Plano de Ação do CMDCA/Altamira, proposta esta motivada pelo juiz da Vara da Infância e da Juventude, no início de 2012, e que culminou com a constituição de um grupo de trabalho, com representantes da NESA, do CMDCA/Altamira, do Ministério Público do Estado (MPE), entre outros, com a incumbência de discutir os critérios e as propostas de alinhamento, mas que somente conseguiu colocar em discussão aquilo que no texto original do PBA poderia ser assumido como políticas compensatórias para o público infanto-juvenil, porém sem avançar para a reformulação destas propostas do PBA tendo em vista as demandas definidas pelo Plano de Ação; (2) elaboração do Pacto de Compromisso entre Consórcio Construtor Belo Monte (CCBM) e o CMDCA/Altamira, em parceria com a Comissão Municipal de Enfrentamento da Violência Sexual Contra Crianças e Adolescentes de Altamira, o qual contém oito medidas voltadas para 0 desenvolvimento de ações de caráter educativo, fiscalizador e financiador, em relação ao enfrentamento da violência sexual contra crianças e adolescentes na região em que se situam os canteiros de obra da UHE Belo Monte, além de fortalecimento do Fundo Municipal dos Direitos da Criança e do Adolescente dos CMDCA dos 11 municípios que compõem a área regional impactada, porém que nunca foi assinado pelo CCBM, apesar das reuniões realizadas entre maio e junho de 2012.

\section{CONCLUSÃO}

A caracterização da situação das crianças e dos adolescentes, da rede de proteção e das políticas públicas voltadas para o público infanto-adolescente no contexto do município de Altamira, tendo em vista os 
impactos sócio-geracionais ocasionados pela construção da UHE Belo Monte, retoma e reforça a discussão a respeito dos modelos de desenvolvimento historicamente implantados na Amazônia e das consequências produzidas para as populações locais.

A disputa por estes modelos de desenvolvimento está a pleno vapor no cenário amazônico, seja por meio das investidas do planejamento estratégico dos órgãos governamentais ou pelas iniciativas de movimentos sociais, povos e comunidades tradicionais e outros segmentos das populações locais de questionarem o caráter colonial da perspectiva hegemônica de desenvolvimento em vigor no Brasil classificada, na atualidade, como neodesenvolvimentismo.

No cerne da questão está a necessidade de valorizar os interesses e vocações produtivas locais para a promoção de desenvolvimento que seja negociado e gerenciado de maneira democrática e sustentável. O cenário de implantação da UHE Belo Monte é o inverso disto e, portanto, só poderia resultar na agudização das condições de vida local e na saturação das instituições e políticas públicas ante 0 avanço dos impactos socioambientais sem mínimo planejamento e investimentos necessários para suportar ou minimizar as situações geradas pela grande obra.

\section{REFERÊNCIAS}

ACSELRAD, $H$. Cartografia social e dinâmicas territoriais: marcos para 0 debate. Rio de Janeiro: Universidade Federal do Rio de Janeiro; Instituto de Pesquisa e Planejamento Urbano e Regional, 2010.

ALMEIDA, A. W. B. Nas bordas da política étnica: os quilombos e as políticas sociais. In: Boletim Informativo do NUER. Florianópolis: NUER/UFSC, v. 2, n. 2, p.15 - 44, 2005.

; SHIRAISHI NETO, J. \& MARTINS, C. C. Guerra ecológica nos babaçuais: 0 processo de devastação das palmeiras, a elevação do preço de commodities e aquecimento do mercado de terras na Amazônia. São Luís: Lithograf, 2005.

.; MARIN, R. E. A. Campanha de (des) territorialização na Amazônia: o agronegócio e a reestruturação do mercado de terras. In BOLLE, W.; CASTRO, E. \& WEJMELKA, M. (orgs.). Amazônia: região universal e teatro do mundo. São Paulo: Globo, p. 141-159, 2010.

BERMANN, C. O projeto da Usina Hidrelétrica de Belo Monte: a autocracia energética como paradigma. In: Novos Cadernos NAEA, v. 15, n. 1, p. 5-23, jun. 2012.

CÂMARA MUNICIPAL DE ALTAMIRA. Lei municipal $n^{\circ} .489$ de 14 de janeiro de 1993. Altamira: 1993. (mimeo)

CAPIBERIBE, A. Um gosto amargo de déjà vu: desenvolvimentismo e os índios. In: . Le Monde Diplomatique Brasil, ano 6, n. 65, p. 5-7, dez. 2012.

CASTRO, E. Políticas de estado e atores sociais na Amazônia contemporânea. In: BOLLE, W.; CASTRO, E.; VEJMELKA, M. (orgs.). Amazônia: região universal e teatro do mundo. São Paulo: Globo, p. 105-122, 2010.

CMDCA. Resolução n ${ }^{\circ}$ 40/2012 - Plano de Ação do Conselho Municipal dos Direitos da Criança e do Adolescente, gestão 20112013. Altamira: mimeo, fev. 2012. 
CONANDA. Carta da $211^{\mathrm{a}}$ Assembleia Ordinária Descentralizada do Conselho Nacional dos Direitos da Criança e do Adolescente. Altamira: mimeo, nov. 2012.

CONSELHO TUTELAR DE ALTAMIRA. Estatística de casos dos conselheiros tutelares de Altamira no período de janeiro a dezembro de 2008. Altamira: mimeo, 2008.

Estatística dos encaminhamentos e casos dos conselheiros tutelares de Altamira do período de janeiro a dezembro de 2009. Altamira: mimeo, 2009.

Estatística dos encaminhamentos e casos dos conselheiros tutelares de Altamira do período de janeiro a dezembro de 2010. Altamira: mimeo, 2010.

Estatística dos encaminhamentos e casos dos conselheiros tutelares de Altamira do período de janeiro a dezembro de 2011. Altamira: mimeo, 2011.

Estatística de atendimento dos casos dos conselheiros tutelares de Altamira de janeiro a dezembro de 2012. Altamira: mimeo, 2012.

CUNHA, M. A. F. A caracterização das populações no EIA/RIMA Belo Monte. In: MAGALHÃES, S. e HERNANDEZ, F. M. (Orgs.). Painel de Especialistas: Análise Crítica do Estudo de Impacto Ambiental do Aproveitamento Hidrelétrico de Belo Monte. Belém: [s.n.], p. 40-42, 2009.

DHESCA. Violações de direitos humanos nas hidrelétricas do rio Madeira. Relatório Preliminar de Missão de Monitoramento. Curitiba: Plataforma DHESCA Brasil, 2010.

GALEANO, E. As veias abertas da América Latina. Porto Alegre: L\&PM, 2011.

HÉBETTE, J. Impacto social dos grandes projetos na Amazônia. In: HÉBETTE, Jean. Cruzando fronteira: 30 anos de estudo do campesinato na Amazônia. Belém: EDUFPA, p. 149-155, 2004.
IBAMA. Parecer n. 168/2012 - Análise do $2^{\circ}$ Relatório Semestral de Andamento do Projeto Básico Ambiental e das Condicionantes da Licença de Instalação 795/2011 da Usina Hidrelétrica Belo Monte. Brasília: IBAMA, 2013.

LEME ENGENHARIA LTDA. Aproveitamento Hidrelétrico (AHE) Belo Monte - Estudo de Impacto Ambiental: Diagnóstico da Área Diretamente Afetada - meio socioeconômico e cultural - ADA Urbana. Brasília: Leme Engenharia Ltda, v. 23, 2009a.

Aproveitamento Hidrelétrico (AHE) Belo Monte - Estudo de Impacto Ambiental: Diagnóstico da Área Diretamente Afetada meio socioeconômico e cultural - ADA Urbana. Brasília: Leme Engenharia Ltda, v. 24, 2009b.

Aproveitamento Hidrelétrico (AHE) Belo Monte - Estudo de Impacto Ambiental: Planos, Programas e Projetos e Conclusões. Brasília: Leme Engenharia Ltda, v. 33, Tomo 1, 2009c.

Aproveitamento Hidrelétrico (AHE) Belo Monte - Estudo de Impacto Ambiental: Planos, Programas e Projetos e Conclusões. Brasília: Leme Engenharia Ltda, v. 33, Tomo 2, 2009d.

LOPES, S. 2009. Audiência Pública de Belo Monte em Belém... Uma Aula de Cidadania? Disponível em: <http://www.socioambiental.org/ banco_imagens/pdfs/depolimento\%20audiencai \%20Belem.pdf.>. Acesso em: 10 fev. 2012.

MAGALHÃES, S.; MARIN, R. E. A. e CASTRO, $E$. Análise de situações e dados sociais, econômicos e culturais. In: MAGALHÃES, S. e HERNANDEZ, F. M. (Orgs.). Painel de Especialistas: Análise Crítica do Estudo de Impacto Ambiental do Aproveitamento Hidrelétrico de Belo Monte. Belém: [s.n.], p. 23 - 35, 2009.

MALERBA, J. \& MILANEZ, B. Um novo código mineral para quê? In: Le Monde Diplomatique Brasil, ano 6, n. 65, p. 22 - 23, dez. 2012. 
MESQUITA, B. A. A dinâmica recente do crescimento do agronegócio na Amazônia e a disputa por territórios. In: SAUER, S. e ALMEIDA, W. (Orgs.). Terras e territórios na Amazônia: demandas, desafios e perspectivas. Brasilia: Editora Universidade de Brasília, p. 45 - 68, 2011.

NESA. Documento de Alinhamento e interfaces entre as políticas básicas e assistenciais constantes no item 2.1 do Plano de Ação do Conselho Municipal dos Direitos da Criança e do Adolescente e o Projeto Básico Ambiental da UHE Belo Monte. Altamira: mimeo, 2012.

NUTI, M. R. Análise das estimativas de população atingida por projetos hidrelétricos. In: VERDUM, Ricardo (org.). Integração, usinas hidrelétricas e impactos socioambientais. Brasília: INESC, p. 57-88, 2007.

PINHO, V. A. e OLIVEIRA, A. C. Relatório final do diagnóstico rápido participativo: enfrentamento da violência sexual contra crianças e adolescentes no município de Altamira. Altamira: [s.n.], 2012.

ROSCOCHE, L. F. Funcionários públicos federais de Altamira desejam sair do município. In: Jorge - Jornal de Geografia, ano 2, n. 13, 2012. Disponível em: $<$ http://jorgedealtamira.blogspot.com.br/>. Acesso em: 30 set. 2012.

SEVÁ FILHO, A. O. Desfiguração do licenciamento ambiental de grandes investimentos (com comentários sobre as hidrelétricas projetadas no rio $\mathrm{Xingu}$ ). Indaiatuba, SP: Comunicação apresentada ao GT História, Sociedade e Meio Ambiente no Brasil, no $2^{\circ}$ Encontro Nacional da ANPPAS Associação Nacional de Pós-Graduação e Pesquisa em Ambiente e Sociedade, maio de 2004.

Povos indígenas, as cidades, e os beiradeiros do rio Xingu que a empresa de eletricidade insiste em barrar. In: Filho Sevá, Arsênio Oswaldo (Org.). Tenotã-Mõ: alerta sobre as consequências dos projetos R. Pol. Públ., São Luís, v. 17, n.2, p. 289 - 302, jul./dez. 2013 hidrelétricos no rio Xingu. São Paulo: IRN, p. 29-54, 2005.

VERDUM, R. Obras de infra-estrutura no contexto da integração Sul-Americana. In: VERDUM, R. (org.). Integração, usinas hidrelétricas e impactos socioambientais. Brasília: INESC, p. 13-40, 2007.

Notas

1 Professor de Direitos Humanos e Diretor da Faculdade de Etnodesenvolvimento da Universidade Federal do Pará (UFPA), Campus de Altamira. Mestre pelo Programa de Pós-Graduação em Direito (PPGD) da UFPA. Coordenador executivo do Instituto de Pesquisa Direitos e Movimentos Sociais (IPDMS). Advogado.

2 Segundo Bermann: "[o] Plano Decenal de Energia 2011-2020 (MME/EPE, 2011) indica a intenção do governo brasileiro de construção de 12 usinas, resultando numa potência de $22.287 \mathrm{MW}$, que representa $65 \%$ do total que o governo pretende instalar no país até 2016 (34.268 MW). Além destas, outras 10 usinas com uma potência total de $15.506 \mathrm{MW}$ estão planejadas e o governo deseja viabilizar as licenças para sua construção até 2020. Por sua vez, o Plano Nacional de Energia 2030 (MME/EPE, 2007) indica um total de 14.000 MW na bacia amazônica, com a pretensão de serem instalados até 2015 , e mais $43.700 \mathrm{MW}$ até o ano 2030, quando o governo pretende atingir um total 156.300 MW de energia hidrelétrica instalada, dobrando a capacidade atual de energia hidrelétrica no Brasil (78.200 MW, em dezembro de 2011)." (2012, p. 8)

3 Para efeito de contextualização, Sevá Filho (2004 e 2005) estabelece retrospecto histórico da UHE Belo Monte com seu "nascimento" institucional tendo ocorrido em 1975 quando se inicia o Estudo de Inventário Hidrelétrico do Xingu pela empresa de consultoria CNEC, pertencente ao grupo da construtora Camargo Correa, e se firma no ano de 1988, quando pela primeira vez a Eletronorte anunciou o projeto de construção de cinco usinas hidrelétricas no rio Xingu e uma no seu principal afluente, o rio Iriri, apelidadas de "Complexo Hidrelétrico de Altamira", sendo a principal delas a então denominada Usina de Kararao, palavra da língua kayapó "grito de guerra", proposta esta que foi sumariamente arquivada ante a repercussão mundial da ação política de lideranças indígenas no "Encontro dos Povos Indígenas em Altamira", em 1989, sobretudo pela cena da indígena da etnia Kayapó Tu-Irá encontstando seu terçado na face atônita do engenheiro José Antônio Muniz Lopes, então representante da Eletronorte neste Encontro. Quase dez anos depois, em 1998, a proposta renasce institucionalmente como programa da campanha de reeleição presidencial, agora chamada de UHE Belo 
Monte, cuja segunda morte foi decretada com a decisão judicial de embarga o Estudo de Impacto Ambiental (EIA) feito pelo órgão ambiental estadual, situação ilegal devido o rio Xingu é bi-estadual (começa no Mato Grosso e percorre grande extensão do estado do Pará) e os impactos socioambientais da obra também serem, o que exigia a condução do estudo e da posterior licença ambiental pelo órgão ambiental federal (IBAMA), o que não foi feito. Só em 2005, como PAC, a obra é retomada pelo planejamento estratégico governamental.

4 Segundo Malerba e Milanez (2012), nos últimos dez anos houve uma inversão na queda dos preços que marcou a historia da exploração dos recursos naturais na América Latina no século XX - sobre esta história, que remonta ao início da colonização das Américas, vale a pena leitura de Galeano (2011) - com o alcance, em 2010, de índice de preços das commodities não energéticas em valores $77 \%$ acima daqueles registrados no ano 2000.

5 As quais Almeida e Marin denominam de agroestratégias, as quais se configuram num conjunto de medidas "... que têm sido adotadas pelos interesses empresariais vinculados aos agronegócios para incorporar novas terras aos seus empreendimentos econômicos, sobretudo na região amazônica, liberandoas tanto de condicionantes jurídico-formais e políticoadministrativos, quando de fatores étnicos e culturais ou determinados pelas modalidades de uso de terras tradicionalmente ocupadas por povos indígenas, quilombolas, seringueiros, quebradeiras de coco babaçu, castanheiros, comunidades de fundos de pasto, faxinais, ribeirinhos, geraizeiros e outras categorias sociais." (Almeida e Marin, 2010, p. 141) As agroestratégias tem como palco central a intensificação da articulação da bancada ruralista no Congresso Nacional, fundamentada nos interesses do agronegócio, para a elaboração de projetos de lei que propõem a modificação da legislação existente em relação ao meio ambiente, aos povos tradicionais e a regulamentação do uso de recursos naturais, sobretudo os energéticos, minerais e madeireiros, tal como ocorreu com a disputa em torno do novo Código Florestal, recentemente editado por meio da Lei $n^{0}$. 12.651/2012. Sobre o assunto, também consultar: Almeida, Shiraishi Neto e Martins (2005) e Capiberibe (2012).

6 Como ressalta Cunha (2009), do Painel de Especialistas, ao criticar a inexistência de análises de dinâmica cultural no EIA-RIMA da UHE Belo Monte, a presença deste componente analítico possibilitaria a identificação de "[u]ma situação de diversidade e de tensão, previsível pelo funcionamento de mecanismos identitários, pois o estudo mostra que a maioria da população residente é nata na região, pode levar a conflitos e ou violências, com repercussões na ordem pública e na saúde psíquica e mental da população. A magnitude das transformações ocasionadas pelo empreendimento vai mudar a escala das representações dessas populações, ou seja, o seu conjunto de valores, crenças, concepções, em relação a todo o seu mundo sócio-biótico, que é a base de suas vidas como pessoas humanas e como sociedade. Conclusões: A estrutura do EIA-RIMA é falaciosa, pois apesar de colocar no EIA dados sobre segurança pública, religiões, escola, hospitais, etc., todos em forma descritiva ou de listagem, tendo, portanto, percepção da amplidão sócio-biótica da população sob jurisdição da influência da $A E H$, falaciosamente a reduz ao critério econômico de PROPRIETÁRIOS, que serve somente aos interesses dos contratadores do EIA, para os seus fins de indenização e expulsão dos atingidos." (CUNHA, 2009, p. 40)

7 Agora em 2013, já se estima um aumento para 140.000 pessoas, porém ainda sem dados técnicos que comprovem esta afirmação. Discute-se, inclusive, a possibilidade de realização de novo Censo do IBGE devido à completa defasagem dos dados censitários apurados em 2010 e as implicações está causando para os repasses de recursos econômicos federais e estaduais vinculados à delimitação populacional, sobretudo na área da educação e da saúde.

8 Realizada no dia 18 de fevereiro de 2013, no plenário da Câmara dos Vereadores de Altamira.

9 Instituição que serve de casa de passagem, apesar de sempre ter funcionado mais como casa de acolhimento.

10 O PBA é a principal política compensatória da UHE Belo Monte, pois grande parte das medidas compensatórias, apesar de se constituir como uma das condicionantes, mas especificamente a condicionante 2.3. da Licença de Instalação.

\section{Assis Costa Oliveira \\ Advogado Pará - UFPA (Campus de Altamira). e Movimentos Sociais (IPDMS).

\author{
Universidade Federal do Pará \\ Rua Augusto Corrêa, 01 - Guamá \\ CEP 66075-110.
}

Mestre em Direito pelo Programa de Pós-Graduação (PPGD) da Universidade Federal do Pará - UFPA.

Professor de Direitos Humanos e Diretor da Faculdade de Etnodesenvolvimento da Universidade Federal do

Coordenador executivo do Instituto de Pesquisa Direitos 